\title{
Antibiotics and the
} Lung

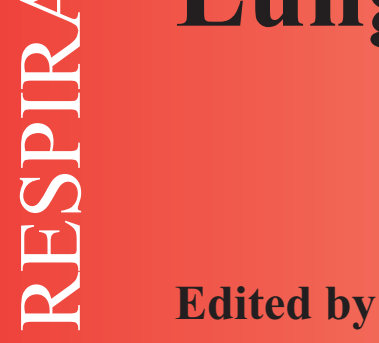

Z M. Cazzola, F. Blasi, S. Ewig

\author{
EUROPEAN \\ RESPIRATORY
} SOCIETY 


\title{
European Respiratory Monograph
}

\section{Antibiotics and the lung}

\author{
Edited by
}
M. Cazzola
F. Blasi
S. Ewig

M. Cazzola is presently Consultant of Respiratory Medicine and Chief of the Respiratory Clinical Pharmacology at the Dept of Respiratory Medicine, at A. Cardarelli Hospital, Naples, Italy. He is also Visiting Senior Lecturer at the Sackler Institute of Pulmonary Pharmacology, GKT School of Biomedical Sciences, London, UK. He is the author and co-author of more than 320 peer-reviewed publications and scientific contributions to books and journals. He currently serves as the Editor for Pulmonary Pharmacology \& Therapeutics, and is an Editorial Board Member for Respiratory Medicine, Respiration, and Monaldi Archives for Chest Diseases. He is also the Chairman of the Airway Pharmacology and Treatment Group of the European Respiratory Society. His research has focused on pharmacology of airway diseases, particularly with the use of bronchodilators in chronic obstructive pulmonary disease and respiratory infections, particularly pharmacokinetics of antimicrobial drugs.

F. Blasi is currently Professor of Respiratory Medicine at the Institute of Respiratory Diseases at the university of Milan, Italy. He is presently the Secretary of the Respiratory Infection Assembly within the European Respiratory Society and is Officer of the Italian Respiratory Society (SiMER). His ongoing research interests include investigations into Chlamydia pneumoniae with respect to its infection incidences and prevalence in chronic bronchitis and HIV infected patients as well as its role in the onset of asthma. Other areas of research include the use of molecular methods in the diagnosis of viral and bacterial infections and antibiotic-resistance detection. He is also working on the role of antibiotics in asthma and chronic obstructive pulmonary disease exacerbations and the role of antibiotic-resistant strains in the outcome of pneumonia.

S. Ewig is professor of medicine and presently Chief of the Dept for Respiratory Medicine and Infectious Diseases at the Augusta-Kranken-Anstalt tertiary care and teaching hospital in Germany. Moreover, he is Lecturer of Respiratory Medicine at the University of Bonn, Germany. He is author and co-author of more than 250 publications and scientific contributions to journals and authoritative books. He has contributed to numerous national and international guidelines for the treatment of adult pulmonary infections. He currently serves as Associate Editor for the European Respiratory Journal. His primary scientific interest includes lower respiratory tract infections (acute exacerbations of chronic obstructive pulmonary disease and community-acquired pneumonia), nosocomial pneumonia as well as pulmonary infections in the immunocompromised host. Ethics in medicine is another important area of his activity.

Purchased by, 


\title{
EUROPEAN RESPIRATORY MONOGRAPH
}

\author{
OFFICIAL PUBLICATION OF THE EUROPEAN RESPIRATORY SOCIETY
}

\section{Editor in Chief}

E.F.M. Wouters, University Hospital Maastricht, Dept of Pulmonology, P.O. Box 5800, 6202 AZ Maastricht, the Netherlands. Tel: 3143 3875044; Fax: 3143 3877087. E-mail: ewo@slon.azm.nl

Secretary: M. Pesik

Tel: 31433875044

Fax: 31433877087

E-mail: mhy@slon.azm.nl

Publications Office: L. Arnold (Publications Manager), ERS Journals Ltd, Suite 2.4, Hutton's Building, 146 West Street, Sheffield, S1 4ES, UK. Tel: 44114 2780498; Fax: 44114 2780501. E-mail: Linda.Arnold@ersj.org.uk

\section{ERS SCHOOL}

\section{Chairman}

K-H Carlsen, Voksentoppen Children's Asthma and Allergy Centre, Ullveien 14, N-0394 Oslo, Norway. Tel: 4722 136500; Fax: 4722136505.

E-mail: harinloedrup.carlsen@ulleval.no

\section{Executive Committee}

President: G.J. Gibson, Newcastle-upon-Tyne Secretary General: C.F. Donner, Veruno Treasurer: L.P. Nicod, Geneva
Past-President: M. Zelter, Paris President-elect: W. McNicholas, Dublin Newsletter Editor: R. Dahl, Aarhus

Programme Committee Chairman: W. MacNee, Edinburgh

Members-at-Large: R. Dahl, Aarhus; C. Gratziou, Athens, A. Chuchalin, Moscow; A. Agusti, Majorca

Monographs may be purchased from the Subscriptions Department, Maney Publishing, Hudson Road, Leeds, LS9 7DL, UK. Tel: 44 1132497481; Fax: 44 1132486983; E-mail: subscriptions@maney.co.uk

\section{Credit card}

Payments through Access, Mastercard, Visa, Amex welcome

All material is copyright to the European Respiratory Society Journals Ltd. It may not be reproduced in any way including electronic means without the express permission of the company.

Business matters (enquiries, advertisement bookings) should be addressed to European Respiratory Society Journals Ltd, Publications Office, Suite 2.4, Hutton's Building, 146 West Street, Sheffield, S1 4ES, UK. Fax: 441142780501

Published by European Respiratory Society Journals Ltd (C2004 


\section{CONTENTS}

Preface a

Introduction

1. Interrelationship of pharmacokinetics/pharmacodynamics: 1 antibiotic dosing for the future

G.W. Amsden

2. Intrapulmonary penetration of antimicrobials and implications in the treatment of lower respiratory tract infections

M. Cazzola, G. D'Amato, M.G. Matera

3. Interaction of antibacterial agents with host respiratory defences

M.T. Labro

4. $\beta$-lactams and the lung

S. Gatermann, T.T. Bauer

5. Macrolides and lower respiratory tract infections

J. Dorca, S. Padrones, F. Manresa

6. Fluoroquinolones and lower respiratory tract infections

A. Kuhnke, H. Lode

7. Treatment of difficult Gram-positive infections

R. Cosentini, P. Tarsia, M. Cazzola, F. Blasi

8. The impact of antibiotic resistance in the management of lower respiratory tract infections

G.C. Schito, A. Marchese

9. Lower respiratory tract infections: when are antibiotics mandatory?

L.A. Mandell

10. Epidemiological impact of antibiotic use/misuse in the community

T. Welte

11. Antibiotics and new guidelines for the treatment of lower respiratory tract infections

G. Di Maria, L. Spicuzza, R. Polosa

12. Are antibiotics useful in acute exacerbations of chronic bronchitis?

F. Blasi, L. Allegra 


\section{The European Respiratory Monograph}

13. Cost-effective antibiotic management of community acquired pneumonia M. Niederman

14. Antibiotic treatment for nosocomial pneumonia

A. de Roux, H. Lode, A. Torres

15. Pharmacological interactions between antibiotics and other drugs in the treatment of lower respiratory tract infections

A. Novelli, E. Mini, T. Mazzei

16. Future antibiotics and current practices for treating respiratory tract infections

D. Ben avid, G. Rahav, E. Rubinstein

Purchased by ,

From: European Respiratory Society Publications (reader.ersjournals.com) 


\title{
EUROPEAN RESPIRATORY MONOGRAPH
}

\author{
Instructions to Authors
}

The European Respiratory Monograph is an official publication of the European Respiratory Society, which publishes "state of the art" review articles, only by invitation, under the coordination of a Guest Editor(s). All manuscripts should be sent to:

E.F.M. Wouters, University Hospital Maastricht, Dept of Pulmonology, P.O. Box 5800, 6202 AZ Maastricht, the Netherlands. Fax: 3143 3875051. E-mail: E.Wouters@lung.azm.nl

\section{INSTRUCTIONS FOR THE PREPARATION OF MANUSCRIPTS}

\section{Presentation}

The manuscript should be accompanied by a presentation letter and a title page, with the name of the authors and their affiliation, the full mailing address, fax number and e-mail address of the corresponding author, and any source of support. A short running head should be given and not more than 6 keywords. The length of a chapter, in typescript form, should be approximately 20-30 pages of double-spaced type including text, figures, tables and references.

\section{Text}

Experimental paper format is not required, and should not include sections on methods, results and discussion. Headings and subheadings should be used to facilitate the readers. The Monograph aims to be educational. Clear distinction should be made between strong information (i.e. based on random, controlled clinical trials) and soft information (i.e. suggestive but inconclusive data). The text should start with an introduction and finish with a 10-15 line conclusion. A brief summary (no more than 300 words) is required with the typescript which should recapitulate the key points, rather than introducing the subjects to be discussed.

\section{Tables and illustrations}

Please include all tables and figures with your typescript. Each chapter must include at least one table or illustration. Every table and illustration must be cited in the text. The source of reproduction must be acknowledged (from [Ref. No.] with permission). See copyright information below.

\section{Tables}

Each table should be typed on a separate page and should have a short title. Other information should appear as footnotes to the table, indicated by superscript symbols. Large tables are difficult to read and print, and should be avoided.

\section{Illustrations}

Where a figure can replace or reduce a text passage, the figure is preferred. Figures should be named and numbered. Line drawings can be supplied as .jpeg, .gif, .tif or .btmp, and will be redrawn into house style. All photographic images should be provided with a minimum of 300 dots per inch (dpi) and should preferably be supplied in .jpeg, .tif or .eps format. Photomicrographs must have internal scale markers (linear scale). Please provide a clear legend for each figure which should be brief and nonrepetitive of information given in the text, all abbreviations should be expanded in the legend.

\section{References}

The author is free to decide on how many references he/she will use. References to original work are preferred to references or quotations from other chapters in the Monograph. However, the author is free to decide on what he/she will quote. Number references consecutively in the order in which they are first mentioned in the text, including those mentioned in tables and figures. Type the references in square brackets. Cite personal communications and unpublished work in the text only, giving the name and initials of the authors and the year of writing. Follow the style of the European Respiratory Journal (Vancouver style).

\section{Copyright}

You must obtain from the copyright holder (usually the publisher of the work) permission to reproduce figures, tables and extended quotations. The source of any such reproduction must always be acknowledged. The original document should be included with your manuscript to the Editor in Chief.

For any further details please refer to the instructions to the authors of the European Respiratory Journal.

Purchased by, 


\section{Preface}

To serve its primary function of gas exchange, the lung is the organ with the largest epithelial surface area in continuous contact with the external environment. The upper and lower airways of humans are repeatedly exposed to airborne particles and microorganisms. Infectious respiratory disorders are therefore an important part of our daily activities as practising physicians. Furthermore, the management of these infectious diseases continues to evolve. Physicians are continuously confronted with new challenges in the cost-effective management of these infectious diseases.

Antibiotic treatment is a key factor in the treatment schedules of these diseases. Optimal treatment would be an antibiotic regimen specifically suited for a specific patient, the type of infection and the infecting pathogen to assure an optimal therapeutic outcome. The present issue of the Monograph not only covers basic knowledge about treatment with antibiotics but also provides state of the art information about a variety of different classes of antibiotics. Indeed, the efficacy of antibiotics traditionally used in the treatment of respiratory infections is increasingly compromised by the emerge of resistant bacteria. Furthermore, state of the art treatment of specific infectious respiratory problems is reviewed in different chapters. This issue of the Monograph also focuses attention on the health economical aspects of antibiotic treatment andon the epidemiological consequences of antibiotic use in the community. State of the art information regarding the management of these diseases is indeed crucial to solve future resistance problems. This issue of the Monograph offers the physician the essential information for state of the art management of infectious problems in daily clinical practice.

\section{E.F.M. Wouters}

Editor in Chief

Eur Respir Mon, 2004, 28, a. Printed in UK - all rights reserved. Copyright ERS Journals Ltd 2004; European Respiratory Monograph; ISSN 1025-448x. ISBN 1-904097-32-4.

Purchased by , 


\section{INTRODUCTION}

Lower respiratory tract infections (LRTIs) are a major healthcare and economical problem due to their high morbidity and to the direct and indirect costs that their management engenders. However, the dimension of the public health problem is not the only reason for the great interest in LRTIs. They are usually treated by antimicrobial agents. Actually, once a diagnosis of LRTI has been made, empirical antibiotic therapy may be justified. When it is, the selection of antimicrobial treatment should be based on a careful clinical assessment of severity, the expected general microbial and resistance pattern and the assessment of the presence of individual risk factors for infection with resistant pathogens. Also having this concept in mind, traditional agents such as $\beta$-lactams and macrolides remain those most frequently used, although they have been compromised by bacterial resistance in the common pathogens e.g. Streptococcus pneumoniae, Haemophilus influenzae and Moraxella catarrhalis. In recent years, there have been worldwide efforts to reduce inappropriate antimicrobial prescribing in response to mounting concerns about the emergence of microbial resistance.

Several guidelines for the management of LRTIs have been published worldwide in response to the move towards evidence-based practice, concern over the misuse of antimicrobial agents and the changes in susceptibility to some of these. However, although the rational use of antibiotics can limit the development of resistances, it is not sufficient to abate the resistant bacteria. The spread of penicillin- and macrolide-resistant $S$. pneumoniae, the increasing emergence of erythromycin-resistant strains of Streptococcus pyogenes, the growing problem with methicillin-resistant staphylococci (MRSA) as well as the emergence of glycopeptide-resistant staphylococci underline the need for therapeutic alternatives. Therefore, new drugs must be designed with emerging needs in mind i.e. specific resistant and hard-to-treat organisms.

The focus of this monograph is on antimicrobial agents and their impact on lungs. For this reason, the readers will find detailed descriptions not only of the advancements in the different classes of antimicrobial agents that are usually prescribed for treating LRTIs, but also of the pulmonary distribution of these agents, the interrelationship between their pharmacokinetic profile and pharmacodynamic action, the interactions between antimicrobial agents and host defences, and the interactions between antimicrobial agents and other drugs. We are confident that consolidated and also novel information on the correct approach to the different forms of LRTI, with particular emphasis on the position of these agents in the new guidelines for the treatment of LRTIs, will add scientific value to these basic findings.

Finally, the description of the therapeutic perspectives in development will confer to this monograph a well-founded hope for an always more effective therapeutic approach to LRTIs and will provide us the opportunity to speculate on the treatment of these infectious conditions in the coming years. 